02

\title{
Разнолигандные комплексные соединения европия (III) с о-метоксибензойной кислотой и фосфорсодержащими нейтральными лигандами
}

\author{
(C) И.В. Калиновская \\ Институт химии Дальневосточного отделения РАН, \\ 690022 Владивосток, Россия \\ e-mail: kalinovskaya@ich.dvo.ru
}

Поступила в редакцию 20.11.2019 г.

В окончательной редакции 16.01.2020 г.

Принята к публикации 24.01.2020 г.

\begin{abstract}
Синтезированы люминесцирующие координационные разнолигандные соединения европия(III) с ометоксибензойной кислотой и фосфорсодержащими нейтральными лигандами островного строения состава $\mathrm{Eu}(\mathrm{MOBA})_{3} \cdot 3 \mathrm{H}_{2} \mathrm{O}$ и $\mathrm{Eu}(\mathrm{MOBA})_{3} \cdot \mathrm{L}$, где MOBA - о-метоксибензойная кислота, L — hmра (гексаметилфосфотриамид), tppo (трифенилфосфиноксид), Et 6 ра (гексаэтилфосфотриамид). Изучены термические свойства комплексных разнолигандных соединений европия (III). Показано, что при термолизе отрыв молекулы нейтрального лиганда происходит в одну стадию с эндотермическим эффектом. Комплексные соединения устойчивы до $280^{\circ} \mathrm{C}$. Установлены состав и строение полученных комплексов. На основании данных ИК спектроскопии показано, что в о-метоксибензоатах европия (III) о-метоксибензойная кислота координируется к иону европия (III) бидентатно.
\end{abstract}

Ключевые слова: люминесценция, соединения европия, о-метоксибензойная кислота, термические свойства.

DOI: $10.21883 /$ OS.2020.05.49318.310-19

\section{Введение}

Люминесцирующие координационные соединения лантаноидов и светотрансформирующие материалы на их основе могут быть использованы в различных устройствах молекулярной электроники: в органических светоизлучающих диодах, лазерах, в различных датчиках [1-6]. Для данных целей широко используются комплексные соединения редкоземельных элементов с о-метоксибензойной кислотой. Так, разнометальный о-метоксибензоат тербий-иттрий с 1,10-фенантролином был успешно использован в качестве компонентов, образующих светоизлучающие слои в электролюминесцентных устройствах [7]. Оптимизация спектроскопических характеристик соединений редкоземельных элементов за счет изменения фрагментов их кристаллических структур является важным этапом в изготовлении высоколюминесцентных лантаноидных материалов, которые могут быть использованы для получения оптических материалов. Факторы, препятствующие эффективному переносу энергии возбуждения на ион лантаноида, должны быть сведены к минимуму посредством изменения состава оптического материала.

Синтезированы и изучены спектрально-люминесцентные свойства соединений европия с метоксибензойными кислотами и азотсодержащими нейтральными лигандами [8-13], комплексные соединения европия с фосфорсодержащими нейтральными лигандами получены не были.
В настоящем сообщении представлены результаты изучения состава, строения, термических свойств разнолигандных комплексных соединений европия (III) с о-метоксибензойной кислотой и фосфорсодержащими нейтральными лигандами состава $\mathrm{Eu}(\mathrm{MOBA})_{3} \cdot \mathrm{L}$, где MOBА - анион о-метоксибензойной кислоты, L гексаэтилфосфотриамид $\left(\mathrm{Et}_{6} \mathrm{pa}\right)$, гексаметилфосфотриамид (hmpa), трифенилфосфиноксид (tppo).

\section{Экспериментальная часть}

Для синтеза разнолигандных комплексных соединений европия с о-метоксибензойной кислотой и фосфорсодержащими нейтральными лигандами использовали следующие реактивы марки ч: шестиводный хлорид европия (III), о-метоксибензойную кислоту, фосфорсодержащие лиганды (гексаэтилфосфотриамид, гексаметилфосфотриамид, трифенилфосфиноксид). О-метоксибензойную кислоту перекристаллизовывали из $90 \%$ этанола.

О-метоксибензоаты европия (III) с фосфорсодержащими нейтральными лигандами получали по следующей методике: к $1 \mathrm{mmol}$ шестиводного хлорида европия (III), растворенного в минимальном количестве дистиллированной воды, приливали $3 \mathrm{mmol}$ о-метоксибензойной кислоты и $1 \mathrm{mmol}$ нейтрального фосфорсодержащего лиганда, растворенных в $15 \mathrm{ml} 90 \%$ этанола. $10 \%$ раствором аммиака доводили $\mathrm{pH}$ рекционной смеси до 5.5-6.0 и оставляли стоять до образования осадка. 
Таблица 1. Результаты химического элементного анализа о-метоксибензоатов европия (III)

\begin{tabular}{|c|c|c|c|c|c|c|c|c|c|c|c|}
\hline \multirow{2}{*}{ Соединения } & \multicolumn{5}{|c|}{ Найдено,\% } & \multicolumn{5}{|c|}{ Вычислено, } & \multirow{2}{*}{$\begin{array}{c}T_{\text {пл }}, \\
{ }^{\circ} \mathrm{C}\end{array}$} \\
\hline & $\mathrm{C}$ & $\mathrm{H}$ & $\mathrm{N}$ & $\mathrm{Eu}$ & $\mathrm{H}_{2} \mathrm{O}$ & $\mathrm{C}$ & $\mathrm{H}$ & $\mathrm{N}$ & $\mathrm{Eu}$ & $\mathrm{H}_{2} \mathrm{O}$ & \\
\hline $\mathrm{Eu}(\mathrm{MOBA})_{3} \cdot 3 \mathrm{H}_{2} \mathrm{O}$ & 43.8 & 4.8 & & 23.1 & 8.6 & 43.5 & 4.5 & & 23.0 & 8.2 & $270-272$ \\
\hline $\mathrm{Eu}(\mathrm{MOBA})_{3} \cdot$ tppo & 60.1 & 4.7 & & 17.5 & & 56.9 & 4.4 & & 17.2 & & $275-277$ \\
\hline $\mathrm{Eu}(\mathrm{MOBA})_{3} \cdot \mathrm{Et}_{6} \mathrm{pa}$ & 59.5 & 4.5 & 3.7 & 12.9 & & 59.1 & 4.3 & 3.4 & 12.5 & & $267-269$ \\
\hline $\mathrm{Eu}(\mathrm{MOBA})_{3} \cdot \mathrm{hmpa}$ & 42.3 & 3.2 & 5.8 & 19.7 & & 47.7 & 5.3 & 5.4 & 19.3 & & $265-267$ \\
\hline
\end{tabular}

Осадок отфильтровывали, промывали водно-этанольной смесью, сушили на воздухе.

Полученные комплексные соединения европия (III) представляют собой мелкокристаллические порошки желтого цвета, растворимые в полярных растворителях, нерастворимые в большинстве неполярных растворителей.

Элементный анализ выполняли на приборе EURO EA 3000. Элементным анализом установлено содержание C и Н в синтезированных комплексных соединениях европия (III). Содержание азота определяли методом Дюма, содержание воды - титрованием по Фишеру (табл. 1). По данным элементного химического анализа состав синтезированных комплексных соединений европия (III) отвечает формуле $\mathrm{Eu}(\mathrm{MOBA})_{3} \mathrm{D}$, где $\mathrm{D}-$ фосфорсодержащий нейтральный лиганд (Et 6 pa, hmpa, tppo) (табл. 1).

Рентгенограммы образцов снимали на дифрактометре ДРОН-1.5 в $\mathrm{Cu} K_{\alpha}$-излучении.

Термограммы комплексных соединений европия (III) получены на дериватографе системы Паулик, Паулик и Эрдей. Скорость нагрева $5 \mathrm{deg} / \mathrm{min}$ (в качестве эталона использовали $\left.\alpha-\mathrm{Al}_{2} \mathrm{O}_{3}\right)$.

Для регистрации ИК спектров поглощения образцов использовался прибор фурье-ИК спектрометр TENSOR-27 фирмы BRUKER (область 350-4000 $\mathrm{cm}^{-1}$, ошибка регистрации частот не более $1 \mathrm{~cm}^{-1}$ ).

\section{Результаты и их обсуждение}

Синтезированные разнолигандные комплексные соединения европия (III) устойчивы на воздухе, не разлагаются при длительном хранении. Методом порошковой дифрактометрии определены кристаллографические параметры комплексных соединений европия (III). Рентгенографическое исследование координационных соединений европия (III) подтвердило их индивидуальность (табл. 2). Проведенный фазовый анализ свидетельствует об отсутствии линий исходных компонентов и возможных примесей. Комплексное соединение состава $\mathrm{Eu}(\mathrm{MOBA})_{3} \cdot \mathrm{Et}_{6}$ ра является рентгеноаморфным.

Для определения состава, получения данных о разложении разнолигандных комплексных о-метоксибензоатов европия (III) проведен их термогравиметрический анализ в интервале температур $25-700^{\circ} \mathrm{C}$. Термическое
Таблица 2. Межплоскостные расстояния и относительные интенсивности рефлексов соединений европия (III) с о-метоксибензойной кислотой и нейтральными лигандами

\begin{tabular}{c|c|c|c}
\hline \multicolumn{2}{c|}{$\mathrm{Eu}(\mathrm{MOBA})_{3} \cdot$ tppo } & \multicolumn{2}{c}{$\mathrm{Eu}(\mathrm{MOBA})_{3} \cdot \mathrm{hmpa}$} \\
\hline$d, \AA$ & $I / I_{0}$ & $d, \AA$ & $I / I_{0}$ \\
\hline 11.85 & 11.3 & 10.85 & 15.0 \\
10.65 & 14.3 & 10.45 & 21.0 \\
9.65 & 24.0 & 9.60 & 16.1 \\
7.78 & 12.0 & 7.96 & 26.0 \\
7.39 & 25.0 & 7.22 & 18.0 \\
6.88 & 100.0 & 6.92 & 100.0 \\
5.27 & 16.7 & 5.43 & 17.4 \\
4.22 & 15.3 & 4.58 & 23.5 \\
3.67 & 12.0 & 3.81 & 15.4 \\
3.37 & 15.0 & 3.27 & 20.1 \\
3.00 & 15.0 & 3.18 & 18.1
\end{tabular}

Таблица 3. Данные термогравиметрического анализа комплексных соединений европия с о-метоксибензойной кислотой и нейтральными лигандами

\begin{tabular}{c|c|c|c|c}
\hline Соединения & Параметры & 1 стадия & 2 стадия & 3 стадия \\
\hline $\mathrm{Eu}(\mathrm{MOBA})_{3} \cdot \mathrm{hmpa}$ & $T\left({ }^{\circ} \mathrm{C}\right)$ & $140-240$ & $250-400$ & 490 \\
& $\Delta m, \%$ & 22.70 & 17.7 & 53 \\
\hline $\mathrm{Eu}(\mathrm{MOBA})_{3} \cdot \operatorname{tppo}$ & $T\left({ }^{\circ} \mathrm{C}\right)$ & $140-245$ & $250-380$ & 494.8 \\
& $\Delta m, \%$ & 31.40 & 25 & 44
\end{tabular}

разложение исследуемых разнолигандных координационных соединений европия протекает сложно и сопровождается рядом эндо- и экзотермических эффектов. Характер разложения полученных комплексных соединений европия (III) однотипен (табл. 3). О-метоксибензоаты европия (Ш) являются термически устойчивыми (до $270^{\circ} \mathrm{C}$ ).

Термолиз о-метоксибензоатов европия (III) с фосфорсодержащими нейтральными лигандами происходит в три стадии. Отщепление нейтральных лигандов протекает в одну стадию в интервале температур $140-240^{\circ} \mathrm{C}$. На кривых TG и DTG этому процессу соответствуют эндотермический эффект с минимумами при 250-270 ${ }^{\circ}$. У данных комплексных соединений европия (III) на конец отщепления нейтрального 
Таблица 4. Важнейшие колебательные частоты $\left(\mathrm{cm}^{-1}\right)$ в ИК спектрах о-метоксибензоатов европия

\begin{tabular}{|c|c|c|c|c|}
\hline HMOBA & $\mathrm{Eu}(\mathrm{MOBA})_{3} \cdot \mathrm{hmpa}$ & $\mathrm{Eu}(\mathrm{MOBA})_{3} \cdot$ tppo & $\mathrm{Eu}(\mathrm{MOBA})_{3} \cdot \mathrm{Et}_{6} \mathrm{pa}$ & Отнесение \\
\hline 1 & 2 & 3 & 5 & 9 \\
\hline 3040 & - & - & & $v(\mathrm{CH})$ \\
\hline 2970 & 2955 & 2954 & 2953 & $v_{\mathrm{as}}\left(\mathrm{CH}_{3}\right)$ \\
\hline 2932 & - & 2924 & - & $v_{\mathrm{s}}\left(\mathrm{CH}_{3}\right)$ \\
\hline- & - & - & - & $\delta\left(\mathrm{H}_{2} \mathrm{O}\right)$ \\
\hline \multirow[t]{2}{*}{1676} & - & - & - & $v(\mathrm{C}=\mathrm{O})$ \\
\hline & & 1680 & & $\begin{array}{c}v(\mathrm{C}-\mathrm{O}) \\
\text { в группе COO }\end{array}$ \\
\hline 1577 & $\begin{array}{l}1590 \\
1508\end{array}$ & $\begin{array}{l}1591 \\
1556\end{array}$ & 1596 & $\nu_{\mathrm{as}}(\mathrm{COO})$ \\
\hline 1491 & - & - & 1496 & $v(\mathrm{C}=\mathrm{C})$ \\
\hline 1457 & 1460 & 1463 & $\begin{array}{l}1462 \\
1436\end{array}$ & $\delta_{\text {as }}\left(\mathrm{CH}_{3}\right)$ \\
\hline- & 1411 & 1402 & 1404 & $v_{\mathrm{s}}(\mathrm{COO})$ \\
\hline 1383 & - & 1377 & 1377 & $\delta_{\mathrm{s}}\left(\mathrm{CH}_{3}\right)$ \\
\hline $\begin{array}{l}1315 \\
1273 \\
1201 \\
1173 \\
1089\end{array}$ & $\begin{array}{l}1286 \\
1139 \\
1093\end{array}$ & $\begin{array}{l}1178 \\
1141 \\
1003\end{array}$ & $\begin{array}{l}1292 \\
1242 \\
1178 \\
1149 \\
1099\end{array}$ & $\begin{array}{c}\delta(\mathrm{CH}) \\
\text { плоские }\end{array}$ \\
\hline- & - & 1556 & 1556 & $v(\mathrm{C}=\mathrm{C})+$ \\
\hline- & - & 1602 & 1604 & $v(\mathrm{C}=\mathrm{N})$ \\
\hline 1020 & - & - & - & $\delta(\mathrm{OH})$ \\
\hline- & $\begin{array}{l}756 \\
688\end{array}$ & $\begin{array}{l}767 \\
639\end{array}$ & $\begin{array}{l}761 \\
738\end{array}$ & $\begin{array}{c}\delta(\mathrm{OH}) \\
\text { неплоские }\end{array}$ \\
\hline
\end{tabular}

лиганда накладывается экзотермический процесс разложения органической части комплекса (отщепление анионов о-метоксибензойной кислоты), сопровождаемый потерей массы, происходящий при $250-500^{\circ} \mathrm{C}$. Поэтому невозможно получить безводное комплексное соединение $\mathrm{Eu}(\mathrm{MOBA})_{3}$. Интенсивная деструкция метоксибензоатов, связанная с образованием оксида европия (III), наблюдается в интервале температур $380-600^{\circ} \mathrm{C}$ с экзотермическим эффектом. Конечным продуктом разложения комплексных соединений является оксид европия (III). Наибольшей термической устойчивостью из синтезированных разнолигандных соединений обладает о-метоксибензоат европия (III) с трифенилфосфиноксидом.

Синтезированные комплексные соединения европия (III) с о-метоксибензойной кислотой и фосфорсодержащими нейтральными лигандами являются более термически устойчивыми (до $270^{\circ} \mathrm{C}$ ), чем изученные ранее трифторацетаты европия [14] и хинальдинаты европия [15], сопоставимы по термической устойчивости с м-толуилатами европия(III) [16].

Изучены ИК спектры комплексных разнолигандных о-метоксибензоатов европия. Отнесение важнейших колебаний проведено на основании сравнительного анализа литературных данных $[17,18]$, ИК спектров исходных веществ (табл. 4, рисунок).

ИК спектры полученных о-метоксибензоатов европия (III) изучались в интервале частот $400-3200 \mathrm{~cm}^{-1}$. Существенное отличие ИК спектров полученных комплексных соединений от спектров исходных соединений и нейтральных лигандов подтверждает получение новых индивидуальных комплексных соединений европия (III).

Сравнительный анализ ИК спектров синтезированных комплексных соединений и о-метоксибензойной кислоты позволил определить способ координации о-метоксибензоат-иона к центральному редкоземельному иону европия. 


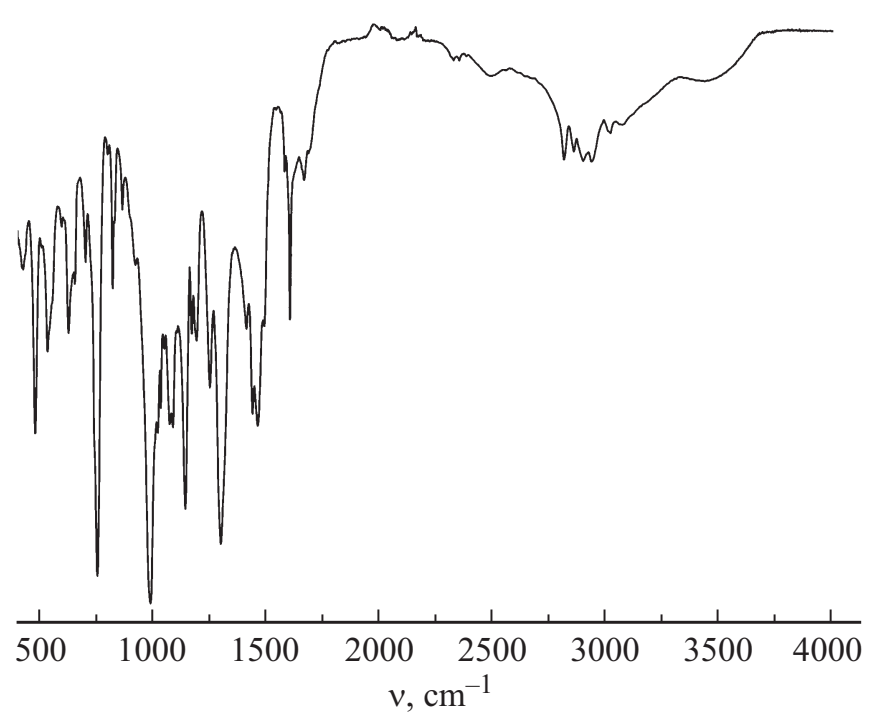

ИК спектр $\mathrm{Eu}(\mathrm{MOBA})_{3} \cdot$ hmpa.

В ИК спектрах разнолигандных комплексных о-метоксибензоатов европия (III) полосы поглощения при 1330 и $1020 \mathrm{~cm}^{-1}$, связанные с деформационными колебаниями ОН-группы свободной о-метоксибензойной кислоты, не проявляются, что указывает на координацию кислоты ионами европия (III) $[17,18]$. У о-метоксибензойной кислоты полосы валентных колебаний карбоксильных групп $\mathrm{COOH}$ лежат в области $1700-1800 \mathrm{~cm}^{-1}$, причем одна полоса - c двумя компонентами расщепления, максимумы которых расположены при 1670 и $1685 \mathrm{~cm}^{-1}$. У разнолигандных о-метоксибензоатов европия с фосфорсодержащими нейтральными лигандами нет полос свободной карбоксильной группы, так как она в соединениях связана с ионом европия (III). В областях 1402-1410 и $1590-1595 \mathrm{~cm}^{-1}$ проявляются симметричные и асимметричные валентные колебания $\mathrm{COO}^{-1}$-групп о-метоксибензоат-иона соответственно [19]. По ряду о-метоксибензоатов европия разность частот $\Delta v=v_{\text {as }}\left(\mathrm{COO}^{-}\right)-v_{\mathrm{s}}\left(\mathrm{COO}^{-}\right)$равна $188-200 \mathrm{~cm}^{-1}$, что указывает на бидентатно-мостиковую координацию карбоксильных групп к ионам европия, а также на ковалентный характер связи $\mathrm{Eu}-\mathrm{O}$ [20]. В ИК спектре $\mathrm{Eu}(\mathrm{MOBA})_{3}$ tрро помимо колебания $v_{\mathrm{as}}\left(\mathrm{COO}^{-}\right)$проявляется дополнительная полоса средней интенсивности при $1680 \mathrm{~cm}^{-1}$, отсутствующая в ИК спектрах других комплексных соединений. Эти данные говорят о наличии (помимо бидентатной) монодентатной координации о-метоксибензоат-иона в комплексном соединении.

ИК спектры в области валентных колебаний связей $\mathrm{C}-\mathrm{C}$ в разнолигандных соединениях и о-метоксибензойной кислоты мало отличаются по числу и интенсивности полос.

О координации фосфорсодержащего лиганда в полученных соединениях говорят появление характеристи- ческих полос поглощения в области $1110-1195 \mathrm{~cm}^{-1}$, отсутствующих в ИК спектрах гидратов о-метоксибензоатов европия. При этом полосы поглощения $v(\mathrm{P}=\mathrm{O})$ в ИК спектрах полученных соединений смещены на $15-30 \mathrm{~cm}^{-1}$ в сторону низких частот по сравнению с их положением в спектрах несвязанных фосфорсодержащих лигандов, что свидетельствует о координации последних через фосфорильный кислород [20].

В области 3050-3080 $\mathrm{cm}^{-1}$ проявляются валентные колебания $v(\mathrm{CH})$ координируемых лигандов. Молекулы воды в синтезированных соединениях отсутствуют. Отсутствуют колебания в области $3400-3800 \mathrm{~cm}^{-1}$ в ИК спектрах полученных метоксибензоатах с фосфорсодержащими нейтральными лигандами [18].

Таким образом, нами установлен состав и строение ряда новых термоустойчивых о-метоксобензоатов европия (III) с фосфорсодержащими нейтральными лигандами. Обнаружено, что в полученных комплексных соединениях европия (III) о-метоксибензойная кислота координируется к иону европия (III) бидентатно. Изучен термолиз соединений.

\section{Финансирование работы}

Работа выполнена при финансовой поддержке Минобрнауки, номер темы государственного задания № 02652014-0001.

\section{Конфликт интересов}

Автор заявляет, что у нее нет конфликта интересов.

\section{Список литературы}

[1] Zhang J., Wang R., Bai J., Wang S. // J. Rare Earths. 2002. V. 20. N 5. P. 449.

[2] Zhang J., Wang R., Yang H., Chin. // J. Anal. Chem. 2003. V. 31. N 4. P. 472.

[3] Hasegawa Y., Nakanishi T. // RSC. Adv. 2015. V. 5. P. 338.

[4] Bunzli J.-C.G., Eliseeva S.V. // Chem. Sci. 2013. V. 4. N 5. P. 1913.

[5] Binnemans K. // Handbook on the Physics and Chemistry of Rare Earths. Elsevier, 2005. V. 35. P. 107-272.

[6] Kataoka H., Kitano T., Takizawa T., Hirai Y., Nakanishi T., Hasegawa Y. // J. Alloys Compd. 2014. V. 601. P. 293.

[7] Shi Y., Deng Z., Xiao J., Xu D., Chen Z., Wang R. // J. Lumin. 2007. V. 122-123. P. 272.

[8] Li X., Bian Z., Jin L., Lu S., Huang S. // J. Mol. Struct. 2000. V. 522. P. 117.

[9] Li X., Zou Y.-Q. // Z. Kristallogr. New Cryst. Struct. 2003. V. 218. P. 445.

[10] Wang R., Li L., Jin L., Lu S. // J. Rare Earths. 1998. V. 16. P. 445.

[11] Gao Z.-H., Wang H., He J.-Y., Wang R.-F. // Acta Cryst. E. 65. 2009. V. 16. P. 1240.

[12] Ma R.X., Chen Z.-M., Gao Z.-H., Wang S.-P., Wang R.-F. // J.J. Zhang Synth. Met. 2009. V. 159. P. 1272.

[13] Jin L., Wang R., Li L., Lu S., Huang S. // Polyhedron. 1998. V. 18. P. 487. 
[14] Калиновская И.В., Карасев В.Е., Зайщева Н.Н., Либар Л.И. // Журн. неорг. химии. 1987. Т. 32. № 4. С. 910.

[15] Калиновская И.В., Задорожная А.Н., Карасев В.Е. // Журн. физ. химии. 1987. Т. 34. № 6. С. 1175.

[16] Zolin V.F. // J. Alloys Compd. 2004. V. 380. N 1-2. P. 101.

[17] Накамото К. Инфракрасные спектры неорганических и координационных соединений. М.: Мир, 1966. 412 с.

[18] Беллами Л. Инфракрасные спектры сложных молекул. М.: ИЛ, 1963. $590 \mathrm{c.}$

[19] Zolin V.F. // J. Alloys Compd. 2004. V. 380. N 1-2. P. 101.

[20] Петроченкова Н.В., Петухова Н.В., Мирочник А.Г., Карасев В.Е. Лифар Л.И. // Коорд. химия. 2001. Т. 27. № 10. C. 790 . 